\title{
TETRALOGY OF FALLOT WITH ABSENT PULMONARY VALVE: A SURGICAL TECHNIQUE FOR COMPLETE REPAIR
}

\author{
Christian Kreutzer, MD,* Andres Schlichter, MD,** and Guillermo Kreutzer, MD,*** Buenos Aires, Argentina
}

Tetralogy of Fallot with absent pulmonary valve syndrome (TOF-APVS) is commonly associated with tracheobronchial compression caused by aneurysmal dilation of the main pulmonary artery and its branches. Surgical repair of this anomaly is focused on correction of the tetralogy of Fallot and relief of the airway compression. Several surgical techniques have been described, such as plication of the pulmonary arteries and valve insertion, ${ }^{1}$ homograft interpositions, ${ }^{2}$ resection of main pulmonary artery and anterior portion of main branches with or without homograft interposition, ${ }^{3}$ and outflow reconstruction without valve insertion. ${ }^{4}$ We report a surgical technique consisting of resection of a generous portion of the walls of the aneurysmally dilated pulmonary arteries and outflow reconstruction with a bicuspid pericardial valve, with the rationale of pulling the pulmonary arteries anterior and downward to relieve bronchial compression.

\section{Patients and methods}

Patients. From January 1997 to December 1997, two patients with TOF-APVS underwent surgical correction at the Ricardo Gutierrez Children's Hospital of Buenos Aires.

PATIENT 1. A 14-day-old girl was referred to our institution because of respiratory failure and mild cyanosis. Her weight on admission was $3.2 \mathrm{~kg}$. Mechanical ventilation was avoided by prone positioning. Diagnosis was confirmed by 2dimensional echocardiography, which showed a pulmonary anulus of $5 \mathrm{~mm}(\mathrm{Z}=-2.42)$, a dilated pulmonary trunk, a right pulmonary artery of $17 \mathrm{~mm}(Z=13.3)$, and a left pulmonary artery of $16 \mathrm{~mm}(Z=11.07)$. The patient underwent an operation at 21 days of age.

PATIENT 2. A 5-month-old boy with mild cyanosis and mild respiratory failure with a history of recurrent admissions for pneumonia and bronchospasm was referred to our hospital. His weight on admission was $5.8 \mathrm{~kg}$. The diagnosis of TOF-

From the Division of Cardiovascular Surgery, Ricardo Gutierez Children's Hospital and Bazterrica Clinic, Buenos Aires, Argentina.

Received for publication Aug 10, 1998; accepted for publication Aug 14, 1998.

Address for reprints: Christian Kreutzer, MD, The Children's Hospital, Department of Cardiovascular Surgery, 300 Longwood Ave, Boston, MA 02115.

*AATS Evarts A. Graham Traveling Fellow, 1998/1999; Instructor in Cardiovascular Surgery.

**Head, Cardiovascular Surgery Unit.

***Head, Cardiac Surgery Division.

J Thorac Cardiovasc Surg 1999;117:192-4

Copyright $(\odot) 1999$ by Mosby, Inc.

$0022-5223 / 99 \$ 8.00+0 \quad \mathbf{1 2 / 5 4 / 9 4 2 2 1}$
APVS was confirmed by 2-dimensional echocardiography and by cardiac catheterization and angiography. This patient had a right pulmonary artery of $20 \mathrm{~mm}(Z=12.77)$, a left pulmonary artery of $21 \mathrm{~mm}(Z=14.85)$, and a pulmonary anulus of $7 \mathrm{~mm}(\mathrm{Z}=-2.1)$.

Surgical technique. Through a median sternotomy, cardiopulmonary bypass at a temperature of $18^{\circ} \mathrm{C}$ was instituted. The pulmonary arteries were completely dissected from hilum to hilum. The main pulmonary artery was transected 1 $\mathrm{mm}$ above the pulmonary anuli, and a longitudinal ventriculotomy was performed. Through 2 lateral incisions toward the hilum and 1 transverse incision, a generous portion of the inferior wall of right and left pulmonary artery (Fig 1, A) and the posterior wall of the pulmonary artery were excised. The posterior aspect of the main pulmonary artery was completely excised. The posterior remnant of the pulmonary trunk was anastomosed (Fig 1,B) with the posterior aspect of the pulmonary anuli with continuous 5-0 polypropylene sutures. In the internal aspect of the anterior wall of the main pulmonary artery a monocusp pericardial patch is constructed. Then, the aorta was crossclamped; crystalloid St Thomas Hospital cardioplegic solution was injected; the parietal band was excised, and the ventricular septal defect was closed with a polytetrafluoroethylene patch. Another monocusp pericardial patch was implanted in the floor of the right ventricle outflow tract (Fig 1,C). After that the aortic crossclamp was released. Rewarming was begun; the pulmonary arteries were reconstructed with the aid of a Hegar dilator according to the body surface area of the patient by the anastomosis of the anterior and posterior edges of the branches. The anterior part of the main pulmonary artery was anastomosed to the edges of the ventriculotomy as a "transannular" patch (Fig 1,D).

Results. Both patients survived the operation. On arrival in the intensive care unit, the patients were prone positioned to improve respiratory mechanics. A selected ventilatory management was instituted to this subset of patients to avoid hyperinflation of the lungs and barotrauma. This included permissive hypercarbia with a carbon dioxide tension of 50 to $60 \mathrm{~mm} \mathrm{Hg}$, low respiratory rates, and very short inspiratory times (0.6 s) with an inspiratory/expiratory ratio of more than 1:4 to prevent air trapping. The use of positive end-expiratory pressure was avoided. Mechanical ventilation was used for 3 days in patient 1 and for 2 days in patient 2. The 2-dimensional echocardiogram at discharge showed normal-sized pulmonary arteries, no significant gradients across the right ventricular outflow tract and pulmonary arteries, and mild pulmonary regurgitation in both patients. At 1 year of follow-up both patients remain well and free of respiratory symptoms, with a normal-size main pulmonary artery and branches. 

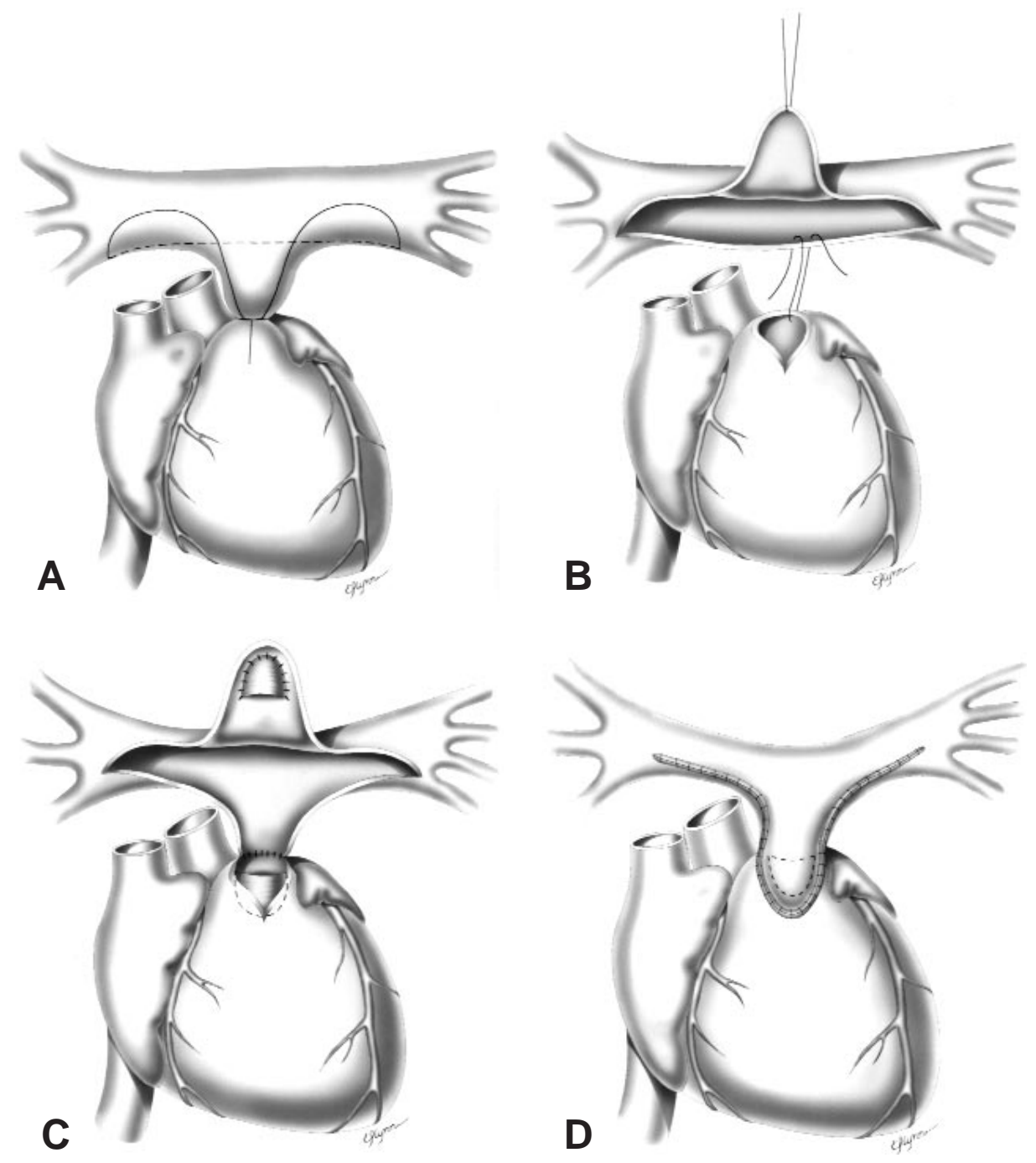

Fig 1. A, Surgical incisions in main pulmonary artery, its branches and right ventricular outflow tract in dotted lines. B, The posterior wall of the main pulmonary artery is excised. The posterior remnant of the main pulmonary artery is anastomosed with the posterior aspect of the pulmonary anulus. C, Monocusp pericardial valves are inserted in the main pulmonary artery and in the floor of the right ventricular outflow tract. $\mathbf{D}$, The branches are reconstructed, and the anterior wall of the main pulmonary artery was anastomosed with the edges of the ventriculotomy as a transannular patch. Note: The aorta and superior vena cava appear transected only for drawing purposes.

Discussion. TOF-APVS is characterized by aneurysmal dilation of the pulmonary arteries and aplasia or rudimentary development of the pulmonary valve with usually a mild hypoplastic anuli. Tracheobronchial compression by dilated pulmonary arteries is common and of critical importance in neonates and infants. In this anomaly, the right and left mainstem bronchi are compressed in their anterior aspect by the dilated pulmonary arteries. To address this problem, the proposed technique aims to cause an anterior and downward traction of the pulmonary arteries with the rationale that such mobilization of the pulmonary arteries will allow complete relief of the anterior compression.
Intensive resuscitation measures for neonates with TOFAPVS and severe respiratory failure have been reported, including sternotomy, prone position, and adequate respiratory management. ${ }^{5}$ The postoperative course of these patients is characterized by respiratory failure with lung hyperinflation by air trapping. In the postoperative period, both of our patients were placed in the prone position, and a special ventilatory management was instituted to avoid barotrauma and lung hyperinflation.

It is a policy of our institution to perform all TOF corrections that require a transannular patch with an autologous pericardial monocusp valved patch. This monocusp valve has 
shown good function in the first few months after the operation and a late insufficiency without obstruction. In these 2 patients, to avoid free pulmonary regurgitation, we decided to use 2 pericardial monocusp valves. The use of native tissue has the advantage of growth potential, and the avoidance of circumferential sutures prevents future reoperations to relieve right ventricular outflow tract obstruction.

In conclusion, we believe that the present technique allows mobilization of the pulmonary arteries to achieve complete bronchial decompression and relief of respiratory symptoms, posing a significant theoretic advantage of growth potential. Long-term follow-up is needed to assess the late results of this approach.

We thank Stella Van Praagh, MD, for constructive criticism on this manuscript.

\section{REFERENCES}

1. McCaughan BC, Danielson GK, Driscoll DJ, McGoon DC. Tetralogy of Fallot with absent pulmonary valve: early and late results of surgical treatment. J Thorac Cardiovasc Surg 1985;89: 280-7.

2. Snir E, de Leval MR, Elliot MJ, Stark J. Current surgical technique to repair Fallot's tetralogy with absent pulmonary valve syndrome. Ann Thorac Surg 1991;51:979-82.

3. Conte S, Serraf A, Godart F, et al. Technique to repair tetralogy of Fallot with absent pulmonary valve. Ann Thorac Surg 1997; 63:1489-91.

4. Karl TR, Musumeci F, de Leval MR, Pincott JR, Taylor FN, Stark J. Surgical treatment of absent pulmonary valve syndrome. J Thorac Cardiovasc Surg 1986;91:590-7.

5. Heinemann MK, Hanley FL. Preoperative management of neonatal tetralogy of Fallot with absent pulmonary valve syndrome. Ann Thorac Surg 1993;55:172-4. 